\title{
The Effect of Heat Treatment on Titania Slag
}

\section{S. Samal ${ }^{a, *}$, B.K. Mohapatra ${ }^{b}$ and P.S. Mukherjee ${ }^{b}$}

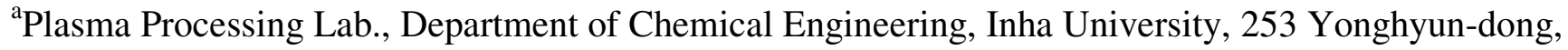
Nam-Gu, Inchon 402-751, South Korea

${ }^{\mathrm{b}}$ Institute of Minerals and Materials Technology, Bhubaneswar 751013, India

*Corresponding author: samasneha@gmail.com

\begin{abstract}
The paper embodies the influence of thermal treatment on the morphology, composition and leaching behaviour of titania slag. When Ti-slag was subjected to heat treatment, it developed pores and oxidized at high temperature. This slag consists mainly of a $\mathrm{M}_{3} \mathrm{O}_{5}$ phase with an orthorhombic structure. The decrepitation was studied by oxidizing the titania slag sample produced in a pot/muffle furnace at temperature $750^{\circ} \mathrm{C}$. Sample oxidized at $750^{\circ} \mathrm{C}$ cracked while sample treated at further high temperature did not show any cracking. The cracking of the samples was linked to decrepitation of the slags which is evidenced from the development of pores in the surface of the sample. From the available information it is postulated that cracks occurs due to change in the crystal lattice of the $\mathrm{M}_{3} \mathrm{O}_{5}$ phase of the slag after oxidation. The present study is directed to a process for the upgrading of titania slags into a product having a very high $\mathrm{TiO}_{2}$ content with low levels of alkaline-earth and other impurities.
\end{abstract}

Keywords: Heat treatment, Titania slag, Oxidation slag.

\section{INTRODUCTION}

Titanium is the ninth most abundant element in the earth's crust. Of the various titanium based products, titanium dioxide $\left(\mathrm{TiO}_{2}\right)$ holds the greatest industrial and commercial significances. It is a high-volume chemical in most of the industrial world. Titanium dioxide is used as pigment in paints, plastics, papers, inks, etc. 
Titanium dioxide $\left(\mathrm{TiO}_{2}\right)$ is commonly found in nature in the form of "ilmenite" ores containing from 30 to $65 \% \mathrm{TiO}_{2}$ in association with varying amounts of oxide impurities of the elements iron, manganese, chromium, vanadium, magnesium, calcium, silicon, aluminum and others. Ilmenite ores are commercially upgraded into titania slag containing typically $70-90 \mathrm{wt} . \% \mathrm{TiO}_{2}$ by electro smelting processes conducted at very high temperatures (molten state) in electric arc furnaces. Ilmenite ores are also upgraded into "synthetic rutile" products containing 92-95wt. \% $\mathrm{TiO}_{2}$ by processes consisting in the leaching of ilmenite ores with mineral acids. "Rutile" is a still richer form of $\mathrm{TiO}_{2}\left(93-96 \% \mathrm{TiO}_{2}\right)$ which occurs naturally but is rarely found in deposits of commercial significance. The production of $\mathrm{TiO}_{2}$ pigments is based on two processes. The traditional "sulfate" process consists in solubilizing ilmenite or slag by dissolving it in concentrate sulphuric acid or in a stream of chlorine gas to produce a vapour mix of chlorides. The main technical requirement for sulfate process feed stocks is that these must be soluble in concentrate sulphuric acid. For the chloride process, however, the main technical requirements are: i) the feedstock must contain low concentrations of alkaline-earth oxides such as $\mathrm{MgO}$ and $\mathrm{CaO}$ and ii) the particle size range must be compatible. In addition, environmental and economic considerations dictate the need for the highest possible $\mathrm{TiO}_{2}$ contents in the feedstock [1].

The present study relates specifically to the preparation of a high grade $\mathrm{TiO}_{2}$ feedstock suitable for the fast growing chloride pigment process by upgrading titania slags. The initial slag can be naturally low in alkaline-earth oxide impurities or could contain higher levels of these impurities. In both the cases resulting upgraded product is of similar $\mathrm{TiO}_{2}$ consists (typically 94-96\% $\mathrm{TiO}_{2}$ ) and exhibit contents of alkaline earth oxides well below the maxima generally acceptable for chloride feed stocks $(1.50 \% \mathrm{MgO}$ and $0.20 \% \mathrm{CaO})$. This is an important aspect of the research since the use of the slags containing higher levels of alkaline-earth oxides has been up to now restricted to the sulfate pigment process. Rock ilmenites, being relatively low in $\mathrm{TiO}_{2}$ contents $\left(30-45 \% \mathrm{TiO}_{2}\right)$ but containing high concentrations of iron oxides, can only be economically upgraded by electro-smelting processes which produce a titania slag and recover the iron values in the form of high purity iron products, the latter feature not being possible in other commercial ilmenite upgrading processes. While electro smelting of rock ilmenites renders the resulting slag suitable as a feedstock for the sulfate process, the smelting doesn't remove sufficient amounts of impurities such as alkaline-earth impurities, including magnesium, manganese and calcium, to make slag suitable as a feedstock for the chloride process. There is therefore a need to provide a commercially attractive method for further upgrading slags obtained from ilmenites, including those ilmenites naturally high in alkaline-earth impurities, to yield a suitable high grade feed stocks for the chloride process of $\mathrm{TiO}_{2}$ production [2].

Unexpectedly, it has been discovered that titania slags can be treated in a novel and commercially efficient process to produce an upgraded slag product which is an excellent feedstock for the chloride process. Thermal plasma technology is one of the suitable processes for the production of high titania slag. As country like India, due to the high power cost, a 
process for the production of titania rich slag has been proposed which can reduce power consumption significantly so that the process can be commercialized. The process essentially consists of two parts. First the ilmenite is pre-reduced/ metallized to about $80-85 \%$ metallization of iron using leco char as reductant and then the metallised ilmenite is plasma melted to separate titania rich slag and iron metal. The Process is having greater significance not only because it is eco friendly but also because both the products mainly titania rich slag and iron metal, are salable high quality material thereby improving the economy of the process [3].

Difference between ilmenite, metalized ilmenite and titania rich slag:

i) Ilmenite ores are found in nature as primary ilmenites $\left(\mathrm{FeTiO}_{3}\right)$ or weather ilmenites and mixtures thereof, where as metalized ilmenite is reduced form of ilmenite and titania slag is produced by electrosmelting or themal plasma melt separation of ilmenite/metalized ilmenite in an electric furnace/ thermal plasma reactor.

ii) The iron present in oxide form in ilmenite has to be reduced before plasma treatment. In metalized ilmenite the iron present in ferric state $\left(\mathrm{Fe}^{+3}\right)$ oxide is transformed into ferrous state $\left(\mathrm{Fe}^{+2}\right)$ oxide form. When the metalized ilmenite undergoes plasma treatment, a large fraction of the iron content of the metallized ilmenite is reduced to metallic iron. The reacted reaction product contains both slag and globules/streaks of Fe metal. Upon slight hammering metallic irons are separated, from slag enriched in titania content [4].

iii) The next difference can be found in the amount of the main components that are present. Ilmenite typically contains around 50\% titanium oxide and around $45 \%$ iron oxide. All the titanium is present as Ti (IV) while around $20 \%$ of the iron occurs as Fe (III) and rest is in the Fe (II) state. In metalized ilmenite titanium oxide contain remain same; where as the most of the Fe (III) is converted into Fe (II) state. Titania slag typically contains around $85 \%$ titanium oxide and around $10 \%$ iron oxide. In this instance the titanium is in the Ti (III) and the Ti (IV) state, while most of the iron present as Fe (II).

iv) The last difference lies in the respective mineralogical compositions. In ilmenite concentrates the iron and the titanium is organized into hexagonal ilmenite crystals. As-cast titania slag consist of the following four phases

i) The most abundant phase is a crystalline phase, known as pseudobrookite or the $\mathrm{M}_{3} \mathrm{O}_{5}$ phase. This phase is a solid solution of iron oxide and titanium oxide, with the end members being ( $\mathrm{Ti}, \mathrm{Fe}, \mathrm{Al}, \mathrm{Cr}, \mathrm{V})_{2} \mathrm{O}_{3} . \mathrm{TiO}_{2}$ and $(\mathrm{Mg}, \mathrm{Mn}, \mathrm{Fe}) \mathrm{O} .2 \mathrm{TiO}_{2}$ and can accommodate the main oxidation states of iron and titanium in its structure namely $\mathrm{Fe}(\mathrm{II}), \mathrm{Fe}(\mathrm{III}), \mathrm{Ti}(\mathrm{III})$ and $\mathrm{Ti}(\mathrm{IV})$; 
ii) Rutile $\left(\mathrm{TiO}_{2}\right)$ although not always present in such quantities that allow detection thereof by X-ray diffraction analysis,

iii) An amorphous, glassy phase consisting mainly of $\mathrm{SiO}_{2}, \mathrm{TiO}_{2}, \mathrm{FeO}, \mathrm{CaO}$ and $\mathrm{Al}_{2} \mathrm{O}_{3}$ and;

iv) Finely disseminated metallic iron globules present in the grain boundaries of the rutile crystals and in the silicate-rich glassy matrix.

The pseudobrookite and amorphous glassy phases are characteristics of titania slag and generally do not occur in ilmenite ores.

After the slag is air quenched, it is crushed and ground to produce fine and coarse products [5 and 6]. These products are used in the downstream processing for the production of titanium dioxide pigment.

The effect of heat treatment on Ti-slag was studied to understand the mechanism of upgrade titania slags by effecting a pretreatment on the slag to provide an intermediate product which is more easily leached of its impurities. Heat treatment is a method to upgrade titania slags to obtain a high $\mathrm{TiO}_{2}$-containg product having residual impurity content and grain size distribution suitable for use as a feedstock in the chloride process of titanium dioxide pigment production, said titania slag containing impurities in the form of oxides of the elements iron, manganese, chromium, vanadium, aluminum, silicon, alkaline-earths and others distributed in a pseudobrookite phase and a glassy silicate phase.

Development of pores related to cracking phenomena of slag is fairly well-known, especially for steel making slags. Decrepitation of slag occurs due to phase and compositional changes and the resultant volume changes. The decrepitation of steel making slags due to an increase in volume of the free lime in the slag during hydration is reported [6]. This problem is particularly faced in the aggregate industry [7 and 8]. Disintegration on cooling of slag containing dicalcium silicate $\left(\mathrm{Ca}_{2} \mathrm{SiO}_{4}\right)$ is due to a transition from the $\beta$ (monoclinic) to $\gamma$ (rhombohedral) structure. Grznek and Derdacka-Grzynek calculated that this transition is accompanied by an expansion in molar volume ( 10\%). Vasyutinskiy and Movsesov [9] studied the oxidation of a high titania slag containing $90.1 \% \mathrm{TiO}_{2}$ and $3.47 \% \mathrm{FeO}$ and reported that to obtain the maximum reduction in strength of the slag, oxidation of the slag in the temperature region of $500-600^{\circ} \mathrm{C}$ was required. Toromanoff and Habashi [10] observed decrepitation in high titania slags (produced at Sorel Canada) constituted of $\mathrm{M}_{3} \mathrm{O}_{5}$ phase, glassy phase, rutile and metallic iron globules during cooling. In this Sorel slag 13.1 mass percent of the total $\mathrm{Ti}$ was present as $\mathrm{Ti}^{3+}$. The decrepitation process was explained by the oxidation of $\mathrm{Ti}^{3+}$ by $\mathrm{Fe}^{2+}$ during the cooling process and due to the 
difference in the coefficients of expansion of the metallic iron and the slag. It was postulated that this process takes place according to the following disproportionation reaction:

$$
\begin{aligned}
& \mathrm{Ti}_{2} \mathrm{O}_{3}+\mathrm{FeO}=2 \mathrm{TiO}_{2}+\mathrm{Fe}^{0} \\
& \Delta \mathrm{G}^{0}{ }_{1000{ }_{\mathrm{C}}}=-71.3 \mathrm{KJ} \mathrm{mol}^{-1}
\end{aligned}
$$

Reid and Ward [11] found that when a solid solution of $\mathrm{Ti}_{3} \mathrm{O}_{5}$ in $\mathrm{FeTi}_{2} \mathrm{O}_{5}$ was formed, the tendency to dissociation decreased and these dissociation reactions might contribute to the decrepitation of high titania slags. The dissociation reactions are given below:

$$
\begin{aligned}
& \mathrm{FeTi}_{2} \mathrm{O}_{5}=\mathrm{FeTiO}_{3}+\mathrm{TiO}_{2}\left[<1150^{\circ} \mathrm{C}\right] \\
& \mathrm{Fe}_{2} \mathrm{TiO}_{5}=\mathrm{Fe}_{2} \mathrm{O}_{3}+\mathrm{TiO}_{2}\left[<585^{\circ} \mathrm{C}\right]
\end{aligned}
$$

This may counter the dissociation reactions or change the temperature at which they occur [12, 13 and 14]. The available information, indicate that high titania slags may decrepitate, due to i) formation of a new phase, ii) volume transformation during heat treatment, iii) development of a polymorphic phase, iv) differences in the co-efficient of expansion of other phases present in the slag.

With this backdrop, hence, the purpose of the present work is to study the decrepitation characteristics of heat treated high Ti-slag obtained during melt separation in a plasma reactor was subjected to heat treatment at $750^{\circ} \mathrm{C}$. The main focus of the paper is to observe the heating effect on the high Ti-slag surface which later enhances the leaching rate to produce synthetic rutile. Figure 1 represents a simplified flowchart of the method of the present study. 


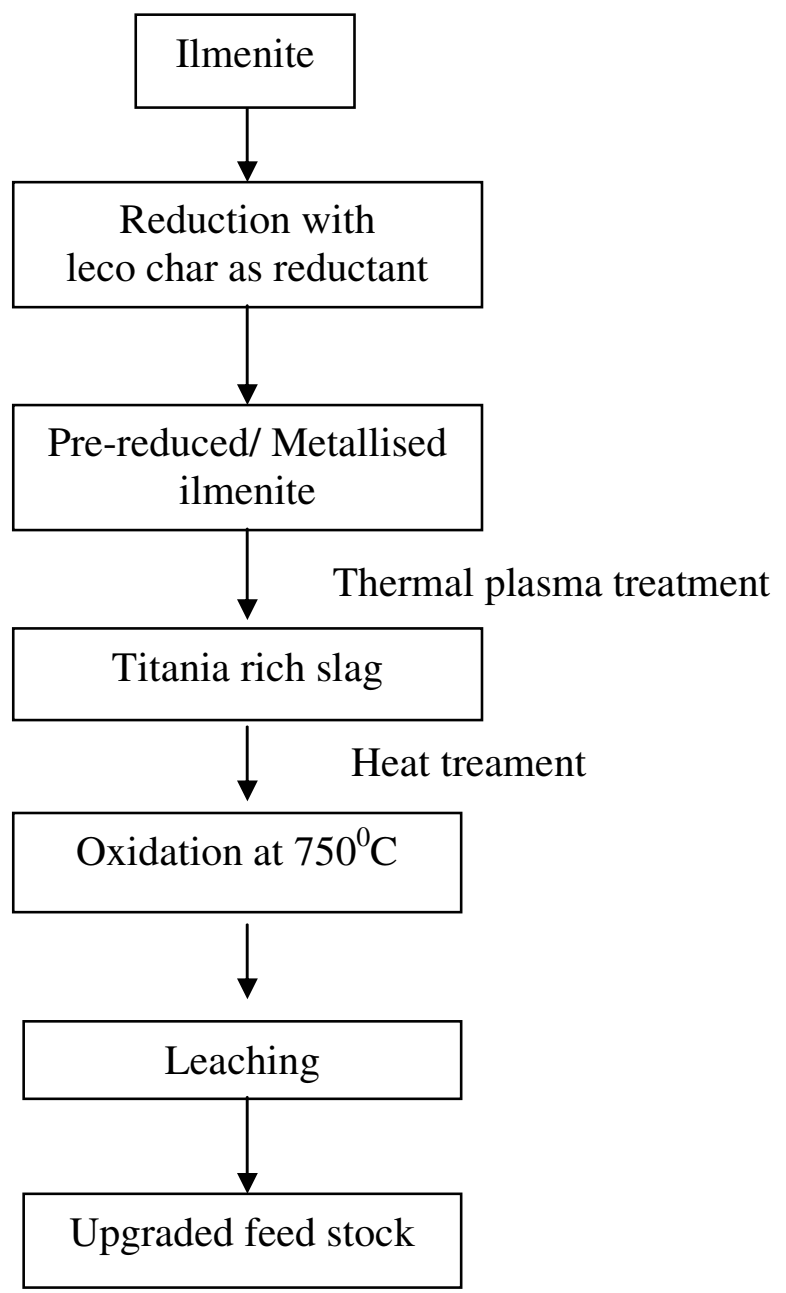

Figure 1. Flowchart of the method of the present study.

\section{EXPERIMENTAL DETAILS}

Feed Ti-slag sample was obtained from metalized ilmenite processed through a plasma reactor. The slag sizing process offers an opportunity to tailor the size distribution of the feedstock to the optimum requirement of the chloride process. Initial titania slag is preferably sized between 75 and 250 microns. Oxidizing the sized slag with an air environment of at least about $750^{\circ} \mathrm{C}$ for a period of at least about 30-120 minutes such that a substantial portion of the iron oxides are converted to the ferric state, such that the reduced titanium oxides are converted to the tetravalent state, and such that at least a major portion of the glassy silicate phase is decomposed. Heating was performed in a pot furnace with a static air atmosphere with slag samples were placed in alumina crucibles, $3.5 \mathrm{~cm}$ in diameters and $2 \mathrm{~cm}$ in high, made of ceramic materials in the hot zone of the pot furnace. 
Phase composition of samples was determined by powder X-ray diffraction technique (Phillips XRD). The surface morphology was observed with a scanning electron microscope (JEOL, JXA8100). The leaching behaviour was studied in the chloride medium, to examine the effect of heat treatment on the slag. A mass of $0.5 \mathrm{~g}$ sample and $50 \mathrm{ml}$ mineral acid were taken with a magnetic stirrer. Leaching experiment was carried out for one hour at around $100^{\circ} \mathrm{C}$ by refluxing the mixture by stirring magnetically. At the end of the leaching, the residue was filtered and washed with water.

\section{RESULTS AND DISCUSSION}

The characteristic changes that took place during thermal treatment of Ti-rich slag are given below:

\subsection{Change in Mineral Phase}

The slag consists mainly of $\mathrm{M}_{3} \mathrm{O}_{5}$ phase, with $\mathrm{M}$ denoting the cations present in the phase (Figure 2). This phase represented by X [(Fe, Mg, Mn) O.2TiO 2 . Y [( $\left.\mathrm{Ti}, \mathrm{Al}, \mathrm{Cr})_{2} \mathrm{O}_{3} . \mathrm{TiO}_{2}\right]$ solid solution. Figure 2 shows a typical X-ray diffraction pattern for titania slag. It shows:

i) A main anatase peak taken at d-spacing of $3.51 \AA$ and a $2 \theta$ angle of $25.445^{\circ}$ for $\mathrm{CuK} \alpha_{1}$ radiation.

ii) A minor pseudobrookite peak (P) taken at a d-spacing of $2.541 \AA$ to $1.513 \AA$ and a $2 \theta$ angle of $35.314^{0}$ to $61.264^{0}$ for $\mathrm{CuK} \alpha_{1}$ radiation.

iii) A minor Iron (D) peak has taken at d-spacing $5.612 \AA$ and a $2 \theta$ angle of $15.771^{0}$ for $\mathrm{CuK} \alpha_{1}$ radiation.

This phase changes during heating at defined pre-determined temperature. At $750^{\circ} \mathrm{C}$ only structural changes in the $\mathrm{M}_{3} \mathrm{O}_{5}$ phase is observed. X-ray diffraction pattern (Figure 3) indicated a distortion of the $\mathrm{M}_{3} \mathrm{O}_{5}$ crystal lattice. Figure 3 shows a typical X-ray diffraction pattern for titania slag after it was subjected to the oxidation procedure. These shows

i) A main rutile peak (r) at a d-spacing of $2.790 \AA$ and a $2 \theta$ angle of $32.037^{\circ}$ for $\mathrm{CuK} \alpha_{1}$ radiation.

ii) A main anatase peak taken at d-spacing of $3.51 \AA$ and a $2 \theta$ angle of $25.445^{\circ}$ for $\mathrm{CuK} \alpha_{1}$ radiation.

iii) A minor ilmenite peak, taken at d-spacing of $2.790 \AA$ and a $2 \theta$ angle of $32.073^{0}$ for $\mathrm{CuK \alpha} \alpha_{1}$ radiation.

iv) A minor pseudobrookite peak (p) taken at a d-spacing of $2.541 \AA$ to $1.513 \AA$ and a $2 \theta$ angle of $35.314^{0}$ to $61.264^{0}$ for $\mathrm{CuK} \alpha_{1}$ radiation. 


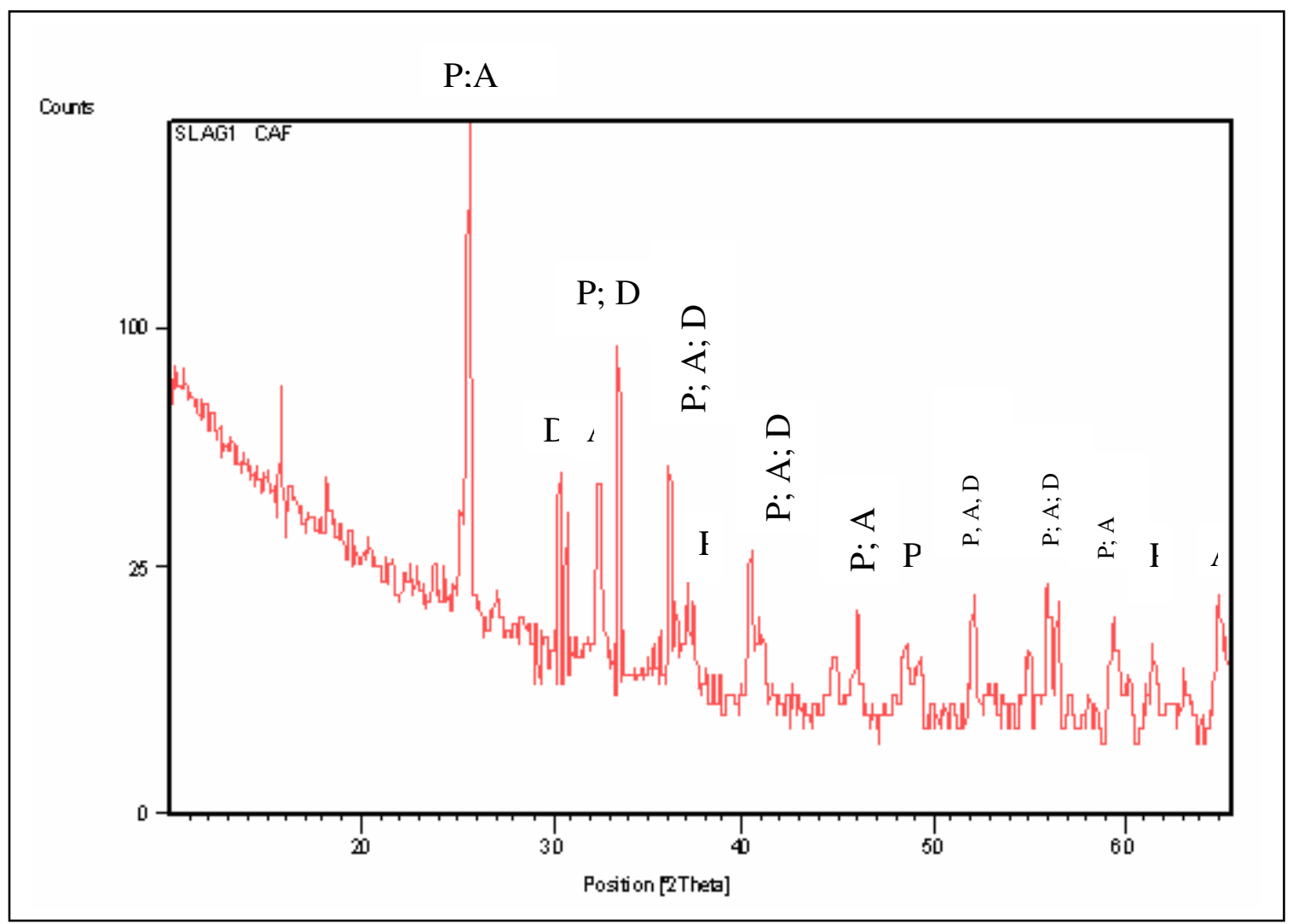

Figure 2. XRD spectrum of typical slag showing Anatase (A), Pesudobrookite (P), Iron phases (D).

The pseudobrookite phase is already freed of $\mathrm{Ti}^{+3}$ constituents from the reduction step which were oxidized during the oxidation step and removed of the pseudobrookite phase as rutile $\left(\mathrm{TiO}_{2}\right)$. Decrepitation of these titania slags takes place during oxidation of $\mathrm{M}_{3} \mathrm{O}_{5}$ phase, to anatase. As the density of anatase is less than the density of the $\mathrm{M}_{3} \mathrm{O}_{5}$ phase, this results in cracking of the slag, which is observed in the SEM figures. 


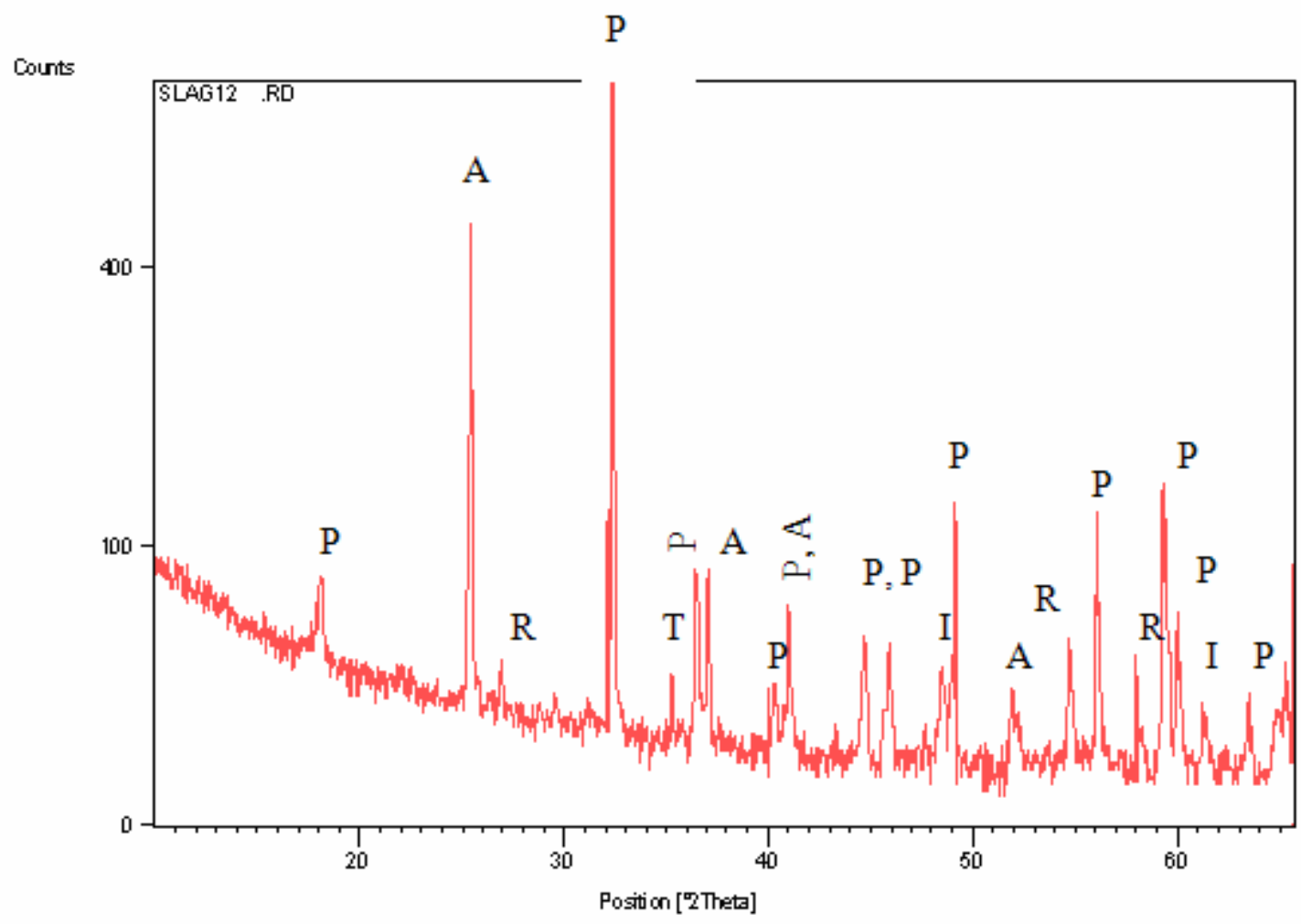

Figure 3. XRD spectrum of Oxidized titania slag showing Anatase (A), Rutile (R), Pseudobrookite $(\mathrm{P})$, Ilmenite $(\mathrm{I})$ and titanium dioxide $\left(\mathrm{Ti}_{3} \mathrm{O}_{5}-\mathrm{T}\right)$ phases.

\subsection{Changes in Morphology}

Figure 4a shows the scanning electron microscope image of the ilmenite. The titania rich slag is represented by Figure $4 \mathrm{~b}$, with two different magnification, clearly shows the metallic iron (bright dots) and with $\mathrm{M}_{3} \mathrm{O}_{5}$ (grey matrix). The Ti-slag under scanning electron microscope appears irregular having small prills balls/ nuggets of iron metals (Figure 4c). The metallic iron normally looks globular and homogenous, although on higher magnification, it contains small inclusion of slag. At higher temperature cracks (Figure 5a) and micro pores (Figure 5b) appear in the slag sample. In the second stage, there is observed a solid state reaction resulting in radical changes in the crystal structure of the slag. Indeed, there is observed the formation of an $\mathrm{MgO}-$ enriched ilmenite-geikielite solid solution, a consequently $\mathrm{MgO}$-deficient residual pseudobrookite phase and a rutile phase. Hence, the $\mathrm{MgO}$ is seen to migrate to the ilmenitegeikielite solid solution, which is fortunately easier to leach than the pseudobrookite. However, during the reduction and oxidation steps, even the residual pseudobrookite phase becomes less 
impervious to leaching by reason of the creation of a large number of pores, channels and other defects in the crystal lattice. Besides iron the slag contains traces of magnesium as impurities (Figure 6a). Similarly, the heat treated slag shows the pores and linear arrangement of Fe and the impurities like Si, Mg were clearly observed (Figure 6b). Oxidized samples revealed that major changes in the general appearance, as well as mineralogical composition of the as-cast slag occurred during the oxidation process. Pores formed and slag particles lost their smooth appearances to become zoned. Some of the larger particles had unoxidized $\mathrm{M}_{3} \mathrm{O}_{5}$ cores surrounded by a $\mathrm{TiO}_{2}$-rich intermediate zone. Most of the smaller particles were transformed to $\mathrm{TiO}_{2}$. The $\mathrm{TiO}_{2}$ phases that formed were a mixture of anatase and rutile. Inside the unoxidized $\mathrm{M}_{3} \mathrm{O}_{5}$ cores of the slag particles fine metallic iron particle, situated at the edges of fine cracks extending through the slag particles. The slag was leached and leached residue was examined under EPMA. The electron micrograph of leached slag residue is illustrated (Figure 6c). Although the major phase in the residue is $\mathrm{Ti}$, it contains appreciable Fe along with impurities of $\mathrm{Mg}$ and trace of $\mathrm{Si}$. The leached residue obtained from heat treated slag displays a higher concentration of titanium in the grains. However, the level of Fe concentration observed in this slag is significantly lower than the leached residue obtained from the slag without heat treatment. This study indicates that leaching of slag after heat treatment could improve the quality of synthetic rutile.

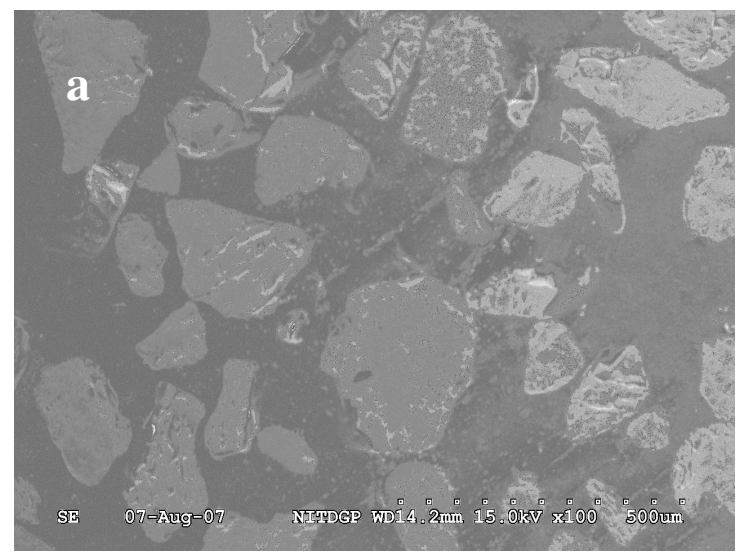

Figure 4a. Electron Micrograph (SEI) ilmenite. 


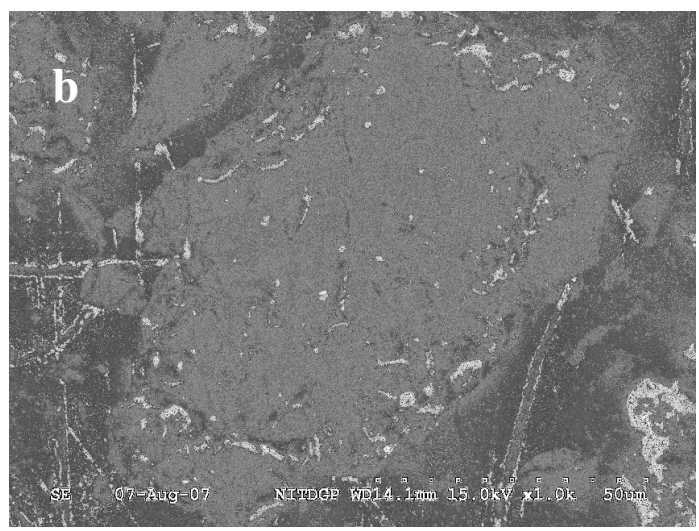

Figure 4b. Titania slag (with higher magnification).

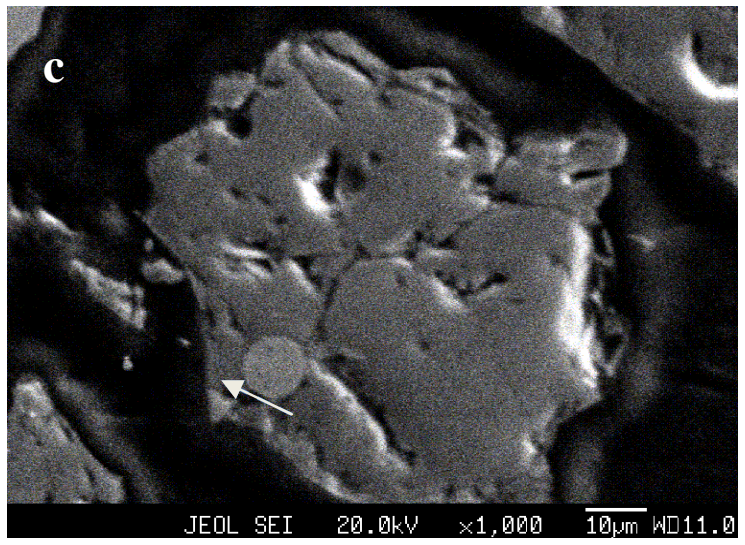

Figure 4c. Electron micrograph (SEI) of a Ti-rich slag sample. (Note: an arrow shows a small globular metal prill within the slag)

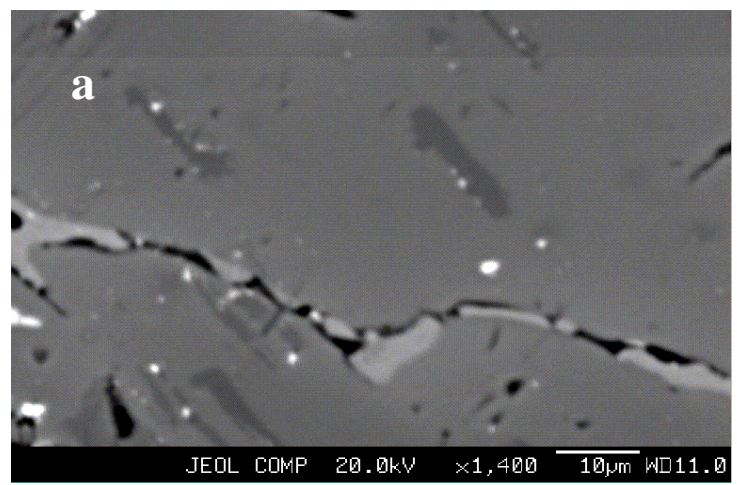

Figure 5a. Electron Micrograph of Heat treated slag (showing crack on the surface) 


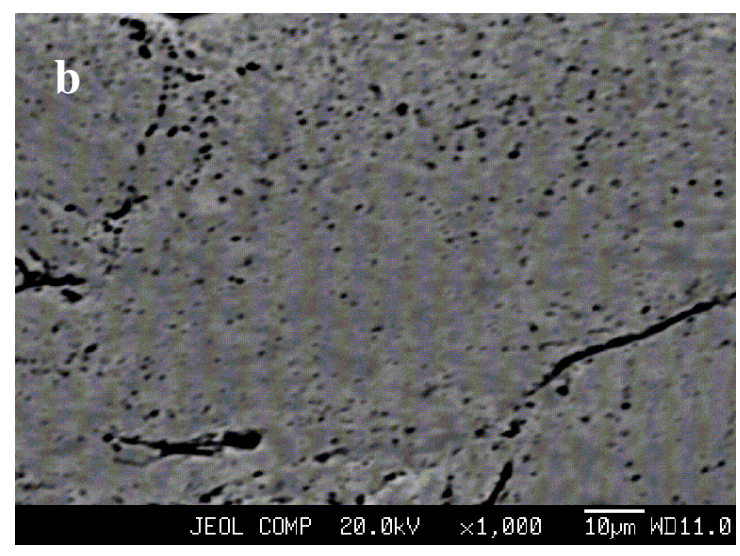

Figure 5b. Electron Micrograph of Heat treated slag (showing pores on the surface)

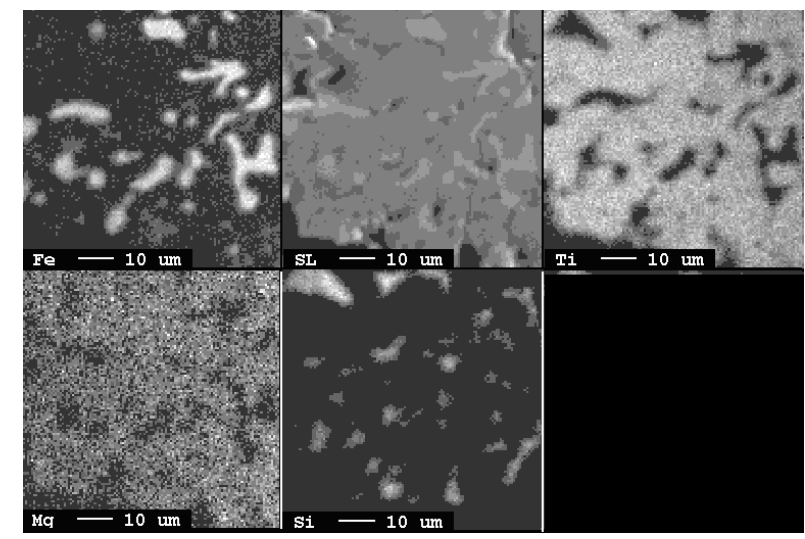

Figure 6 a. Electron micrograph (SEI) of a Ti-rich slag sample and distribution of Fe, Ti, and Al in selected area (SL)

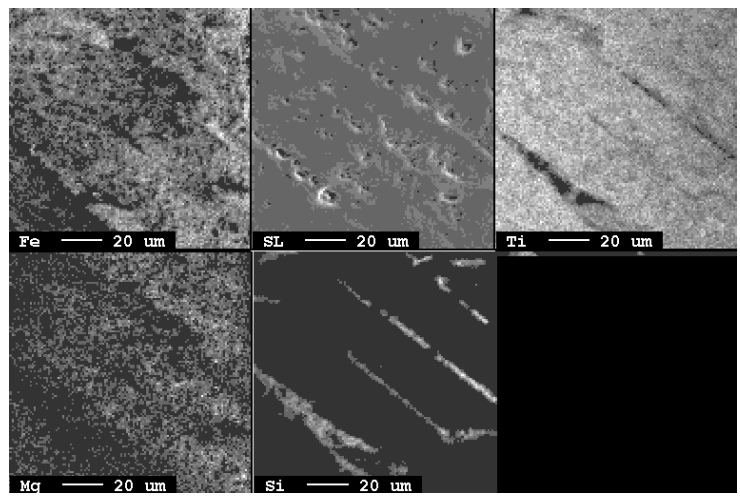

Figure $6 \mathrm{~b}$. Electron Micrograph of heat treated Slag and distribution of Fe, Ti and $\mathrm{Al}$ in selected area (SL) 


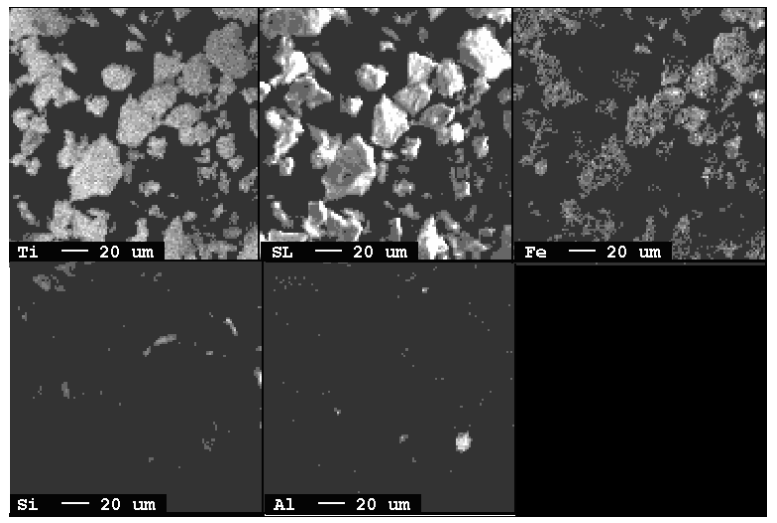

Figure 6c. Electron Micrograph of Heat treated slag after leaching and distribution of Fe, $\mathrm{Ti}, \mathrm{Si}$ and $\mathrm{Al}$ in selected area (SL)

\subsection{Chemical Analysis of Slag, Leached Slag and Heat Treated Slag after Leaching}

Chemical analysis of slag, leached residue of slag and leached residue of heat treated slag were carried out to know the compositional variation between them. Leaching time was 1 hour at temperature of $100^{\circ} \mathrm{C}$. The leaching vessel was a conical flask with cooling system. The system was kept on a heating plate maintained at $95\left( \pm 5^{0}\right) \mathrm{C}$. The container had a mechanical agitator turning at $30 \mathrm{rpm}$. Residence time in the apparatus was about 60 minutes. The weight $\%$ of $\mathrm{Ti}$ gradually increases from slag to slag with leaching then to heat treated slag after leaching in contrast Fe that shows a decreasing trend. The analysis results of these samples are shown in Table 1 and 2.

Table 1: Chemical Analysis of Titania rich Slag

\begin{tabular}{|ll|}
\hline Composition & \% \\
\hline $\mathrm{TiO}_{2}$ & 84.5 \\
\hline $\mathrm{Metallic} \mathrm{Fe}$ & 2 \\
\hline $\mathrm{FeO}$ & 11 \\
\hline $\mathrm{SiO}_{2}$ & 0.19 \\
\hline $\mathrm{Cr}_{2} \mathrm{O}_{3}$ & 0.02 \\
\hline $\mathrm{CaO}$ & 0.26 \\
\hline $\mathrm{MgO}$ & 1.3 \\
\hline $\mathrm{MnO}$ & 0.73 \\
\hline
\end{tabular}


Table 2: Chemical composition of the residue of the leached slag (upgraded feed stock).

\begin{tabular}{|lc|}
\hline Constituents & Percent \\
\hline $\mathrm{TiO}_{2}$ Content & 93.05 \\
\hline Total Fe Content & 3.58 \\
\hline $\mathrm{Cr}_{2} \mathrm{O}_{3}$ & 0.06 \\
\hline $\mathrm{CaO}$ & 0.13 \\
\hline $\mathrm{MgO}$ & 0.23 \\
\hline $\mathrm{MnO}$ & 0.53 \\
\hline $\mathrm{SiO}_{2}$ & 0.02 \\
\hline
\end{tabular}

\section{CONCLUSION}

This study indicates that leaching of slag after heat treatment could improve the quality of the synthetic rutile. The slag produced from thermal plasma reactor was heat treated at $750^{\circ} \mathrm{C}$ for half an hour. Generally, high titania slags consist mainly of a $\mathrm{M}_{3} \mathrm{O}_{5}$ phase $(\mathrm{M}$ : $\mathrm{Ti}, \mathrm{Fe}$ ) phase with an orthorhombic structure. At higher temperature, the cracking of the samples was linked to the decrepitation of the slags. The decrepitation occurs due to changes in the crystal lattice of the $\mathrm{M}_{3} \mathrm{O}_{5}$ phase of the slag. Heat treatment method of treating a titania slag to obtain an intermediate product. That includes rutile, pseudo-brookite and ilmenite. Titania slag containing reduced titanium oxides and impurities including at least one member selected from the group consisting of iron oxide, manganese oxide, chromium oxide, aluminum oxide, silicon oxides and alkalineearth oxides, said at least one member being distributed in a pseudo-brookite phase and a glassy silicate phase. A titaniferous intermediate product produced by the process of heat treatment, which includes rutile and pseudobrookite phase. The iron which is successfully removed is in fact metallic iron, which can precipitate by the disproportionation reaction which is triggered by slight oxidation.

Heat treatment of slag was found to be very effective in leaching of Fe from the complex matrix of the slag. This may be due to the formation of new phases during heating as compared to the normal slag. Further, heat treatment also improves leachability by developing cracks in the particles. 


\section{ACKNOWLEDGEMENTS}

The first author would like to acknowledge Dr. A. K. Ray, Scientist (for correction of the

manuscript) from Material Characterization Department, National Metallurgical Laboratory, Jamshedpur, India.

\section{REFERENCES}

1. K. Borowiec, A.E. Grau, M. Gueguin and J.-F. Turgeon: "Method to upgrade titania slag and resulting products." US Patent number 5,830,420, Nov.3, (1998).

2. J.P. Van Dyk, N.M. Vegter, C.P. Visser, T. de Lange, J.D. Winter, E.A. Walpole and J. Nell: "Beneficiation titania slag by oxidation and reduction treatment". US Patent number 6,830,024 B1, Oct.12, (2004).

3. P.S. Mukherjee, T.K. Mukherjee, V.N. Misra, Trans. Indian Inst. Met.57 February 7, (2004), P. 71-77.

4. S. Samal, B.K. Mohapatra, P.S. Mukherjee and S.K. Chatterjee, "Integrated XRD,EPMA and XRF study of ilmenite and titania slag used in pigment production" J. alloys and compounds, Vol.474, $17^{\text {th }}$ April (2009), P. 484-489.

5. J.R. Fisher, Heavy Minerals 1997, South African Institute of Mining and Metallurgy, Johannesburg, (1997), P. 207.

6. I. Robinson, Engineering news-mining (22 Apr.1994) P. 31.

7. F. Noguchi, T. Nakamura, Y. Ueda, T. Yanagase, Australia/Japan Extractive metallurgy Symposium,Sydney,Australia,16-18 July 1980, Australasian Institute of mining and Metallurgy, Parkville, Victoria,(1980),P. 479.

8. L.M. Juckes, Commission of the European Communities - technical Steel Research, Report no. EUR 13430, (1991).

9. J. Grzymek, A. Derdacka-Grzymek, Light metals 1990, Anaheim, California, February 1990, P. 18-22.

10. A. Okamoto, E. Futamura and K. Kawamura, Trans. Iron steel Inst.Jpn.21 1 (1981), P. 16.

11. N.A. Vasyutinskiy and E.E. Movsesov. Russ.Metall. 1 (1965), P. 56.

12. I. Toromanoff and F. Habashi, J.Less-Common Met.97 (1984), P.317.

13. A.F. Reid and J.C. Ward. Acta Chem.Scand.25 4 (1971), P. 1475.

14. D. Bessinger, J. M. A. Geldenhuis, P. C. Pistorius, A. Mulaba, G. Hearne, The decrepitation of solidified high titania slags", Journal of Non-Crystalline Solids, Volume 282, Issue 1, April (2001), P. 132-142. 